\title{
THE METRIC SYSTEM IN MEDICINE AND PHARMACY
}

BY

\section{W. C. W. NIXON, M.D., F.R.C.S., F.R.C.O.G. AND}

\section{T. D. WhitTet, B.Sc., Ph.C., A.R.I.C.}

The replacement of the archaic apothecaries', avoirdupois, and imperial systems of weights and measures by the metric system has long been advocated by progressive doctors and pharmacists. As long ago as 1826 Andrew Duncan ${ }^{1}$ pointed out the inconvenience of imperial and apothecaries' measures and suggested the use of decimal multiples of the grain. An annotation on his letter in the Lancet $^{2}$ approved this suggestion in principle but recommended that, "instead of adopting an alteration of weights for pharmacy, as proposed in this letter, it would be more advisable to wait a little, until the Government shall ordain the decimal proportions of weights and measures to be generally used, which we anticipate to see done in a few years" (our italics).

In 1944 one of us (W. C.W. N. $)^{3}$ advocated in this Journal a change to the metric system. This gave rise to considerable correspondence, ${ }^{4-10}$ all in favour of the proposed change. Following this metric equivalents were introduced into all articles published in the British Medical Journal.

The British Pharmacopoeia Commission has advocated that the medical and pharmaceutical professions should use the metric system exclusively, and since 1914 all the formulae of the Pharmacopoeia have been expressed in the metric system, while doses have been given in both metric and imperial. It is interesting to note that in the preface to the 1914 pharmacopoeia the following statement occurs: "The metric system has also been employed for the specification of doses, in the expectation that in the near future the system will be generally adopted by British prescribers" (our italics). The British Pharmaceutical Codex employs both imperial and metric systems side by side in all its formulae, monographs, and doses.

\section{Archaic Systems}

From the teaching point of view, we regard it as a retrograde step that on entering his clinical course the student has to be taught the archaic systems of weights and measures. During his preclinical pharmacology course he is accustomed to using drugs in terms of the metric system and has also used that system in his other scientific subjects. He must therefore gain the impression from the old-fashioned systems that clinical medicine and pharmacy have lagged behind the other sciences and still cling to outmoded methods. Since the war English textbooks of medicine and pharmacy are being used to an increasing extent in many Continental countries; therefore it is most important that the metric system should be used in such publications.

As Bodenham has pointed out, ${ }^{11}$ it is the custom for all new drugs to be measured for dosage in terms of the metric system, and hence the proportion of commonly used drugs measured in the apothecaries' system is steadily decreasing. This trend has brought the farcical state of affairs that older analgesics, such as morphine and diamorphine, are almost invariably prescribed in fractions of a grain, whereas the very similar newer synthetic analgesics, such as pethidine and methadone (amidone), are always prescribed in milligrammes. Many similar examples could be quoted. Since most hypodermic syringes are graduated in the metric system it is not uncommon to find mixtures of the two systems used for injections-for example, atropine sulphate $1 / 100 \mathrm{gr}$. in $1 \mathrm{ml}$.

This multiplicity of systems leads to confusion and serious or even fatal errors, and there seems little excuse for retaining the obsolete apothecaries' and imperial systems.

\section{Government Report}

Some years ago a Committee on Weights and Measures Legislation was set up by the Board of Trade with the following terms of reference: "To review the existing weights and measures legislation and other legislation containing provisions affecting weights and measures and administration thereof, and to make recommendations for bringing these into line with present-day requirements." This committee, after hearing evidence from the British Medical Association, the Pharmaceutical Society, and other interested bodies, issued its report in $1951 .^{12}$

The recommendations were (1) that the apothecaries', troy, and pennyweight systems of measurement should be abolished after five years, and the trades and professions at present using them should adopt the metric system in their place; (2) that the Board of Trade should define suitable tolerances for metric weights and measures (the British Standards Institute is at present drawing up standards for metric measures); and (3) that the Government should take steps in concert with the Commonwealth and the U.S.A. to abolish the imperial system of measurement over a period of about 20 years.

In its evidence to this committee the British Medical Association stated that the medical profession is probably in favour of using the metric system, but that abolition of the apothecaries' system would cause some hardship to the middle and older generation of doctors. The Pharmaceutical Society favours the change, provided that doctors cooperate in writing all their prescriptions in the metric system and do not leave it to the pharmacist to translate apothecaries'-system prescriptions into the metric system.

In the early part of 1952 the Association of British Pharmaceutical Industry made an important decision which will have the effect of implementing some of the recommendations of the Board of Trade Committee. The association decided that, from early 1953, all galenicals and pharmaceuticals should be sold on the metric system in pharmacy. This has the support of the Pharmaceutical Society and the Guild of Public Pharmacists.

The Association of British Pharmaceutical Industry has also approached the Glass Manufaçturers' Federation with a view to the standardization of a range of bottles suitable for metric quantities from $25 \mathrm{ml}$. up to $2 \frac{1}{2}$ litres. If this can be arranged it would facilitate a transition to the metric system for medicines.

\section{Government Reluctance}

In the House of Commons on May 10, 1951, the then President of the Board of Trade, giving a written answer to a question, said that among the recommendations of the Board of Trade Committee were some which the Government could not accept, at least for immediate implementation. The proposal that the Government should take steps towards the eventual complete adoption of the metric system in this country clearly raised most important issues which could not be determined without lengthy and most serious consideration. On November 11, 1952, the President of the Board of Trade stated that the Government was not prepared to proceed with the recommendation for the eventual abandonment of the imperial for the metric system of weights and measures.

These statements by two different Governments make it clear that we cannot expect the adoption of the metric system to come by legislation, and if the professions wish it they must make their own decision. The reluctance of the Governments to take such a step is probably because of the 
expense and inconvenience involved in the recalibration of machine tools and precision instruments. These factors would not affect medicine and pharmacy.

The main objections to the metric system are the fear of a misplaced decimal point leading to gross overdosage and the difficulty of memorizing doses in fractions of a gramme. Both of these disadvantages could be overcome by the use of milligrammes, centigrammes, etc., as has been advocated by Beard. On the whole the few disadvantages of the metric system would be greatly outweighed by the abolition of the present confusion and general simplification of measurements which would result from its exclusive adoption in medicine and pharmacy.

\section{Overnight Change}

We realize that the change we advocate would mean a certain amount of hardship to those who had to change their prescribing habits with the older drugs, but we consider the eventual result would justify this. As Marsh ${ }^{5}$ has pointed out, the change would cause no more disturbance than the introduction of a new British Pharmacopoeia or British Pharmaceutical Codex.

On the whole we favour an "overnight" change (after due notice had been given) rather than the gradual change suggested by the Board of Trade Committee. We are impressed by the letter of Lambert Rogers ${ }^{\circ}$ giving an analogy with an overnight change of nautical helm orders some years ago. Critics had predicted many dire consequences of this sudden change, whereas in practice it took place without mishap or confusion. We urge that the General Medical Council, the British Medical Association, the Pharmaceutical Society, and the universities and other examining bodies should take action to implement this change, otherwise the present confusion is likely to continue indefinitely and we shall be the sole country out of step with the rest of the world, just as we are one of the few remaining who drive on the left of the road and call surgeons "Mr."

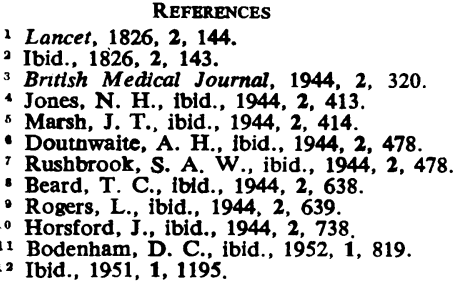

Leander Starr Jameson, remembered as the leader of the famous "Jameson Raid," was born on February 9, 1853. He studied medicine, and qualified from University College Hospital, London, in 1875. After a short time in practice in this country he emigrated to Kimberley, in South Africa, where he soon built up a great reputation. As a result of his friendship with Cecil Rhodes he undertook three fruitful missions to the Matabele chief Lobengula, from whom Rhodes had obtained concessions of mineral rights. Jameson later became administrator of Mashonaland, and by 1894 had reached the zenith of his fame. About this time the discontent of the "Uitlanders" with the Transvaal Government was coming to a head, and plans were being made for its forcible overthrow. Jameson undertook the task of raising a mounted force in Rhodesia and holding it in readiness for any eventuality. In defiance of wiser counsels he entered on his historic "Raid" by crossing the Transvaal border on December 29, 1895. His force was soon defeated by the Boers, and Jameson was handed over to the British authorities, being eventually sentenced in London to 15 months' imprisonment. He was released for health reasons and soon came to the fore again, becoming Prime Minister of Cape Colony in 1904 and the foremost figure in South African politics. He worked in amity with Botha to achieve the Union. In 1911 a baronetcy was conferred on him. Continued ill-health led him to return to England, where he died on November 26, 1917.

\section{Nova et Vetera}

\section{ARCHITECT OF PUBLIC HEALTH}

The Life and Times of Edwin Chadwick. By Professor S. E. Finer. (Pp. 555. £2 2s.) London: Methuen and Co. 1952.

It has often been regretted that, although Edwin Chadwick was the great architect of social and public health administration in the first half of the nineteenth century, no fullscale biography of this remarkable man has been written. His admirer, Benjamin Ward Richardson, in editing in 1887 a selection of Chadwick's papers entitled The Health of Nations, prefaced the book by a short life in which Chadwick himself took great personal interest, and brief lives have also been written by Marston and others; but these studies obviously omit much in the telling. This deficiency has now been supplied by Professor Finer's full and scholarly biography.

The author traces the stages of Chadwick's meteoric career ; first, the attorney's clerk and barrister, and the formative years when he sat at the feet of Jeremy Bentham.

"The influence of legal training and, in particular, the legal models of Bentham and the French codes fostered a mental attitude which he never shook off and which determined his approach to all social problems he afterwards investigated.'

Secondly, the arbiter, motive power, and director of the Poor Law Commission, where his draconian methods, satirized in Oliver Twist, led to his dismissal in 1847.

But his famous General Report on the Sanitary Condition of the Labouring Population of Great Britain, the opening cannonade of a century of public health reform, had appeared in 1842, and a Royal Commission was appointed which confirmed Chadwick's indictment of the terrible conditions of social degradation and disease which prevailed in this country.

The Public Health Act of 1848 was passed, and Chadwick entered on the third stage of his career as the moving spirit of the General Board of Health, being associated as Commissioner with the First Commissioner of Works (ex officio) and Lord Ashley. Professor Finer shows how Chadwick's intolerance and fanaticism, qualities fatal to human relations, defeated the very ends which he had in view. "Unable to bend, he was made to be broken." As he disdained compromise and ignored opposition in his zeal for publichealth reform in a hurry, public opinion denounced him, and to placate it Lord Palmerston persuaded him to resign on a pension in 1854. The rest of Chadwick's long life was an anticlimax, though he continued to advocate publichealth reform incessantly and witnessed its triumphs. In the year before his death he received belated recognition by the bestowal of the K.C.B.

If at times the author dwells too much on "old unhappy far-off things and battles long ago," he has on the whole faithfully depicted the shadows as well as the highlights of Chadwick's character. The self-arrogant Chadwick was ungrateful to Southwood Smith, Neil Arnott, Kay, and others. Although these medical pioneers had brought to his notice the sanitary crimes he assailed and had instructed him in the means for combating them, he looked on doctors "as necessary evils and not very likely to last."

Nevertheless, Chadwick was a great man. He re-forged four distinct social services and reformed the entire system of local government. When his colleagues were unmoved by injustice, poverty, dirt, and disease, Chadwick assailed these evils and prodded the apathetic into activity. That is why the Prince Consort, Lord Shaftesbury, Sir John Simon, and other enlightened men of those days esteemed his work, and why medicine and public health reap to-day the reward of his labours, so admirably set forth in this authoritative biography. 